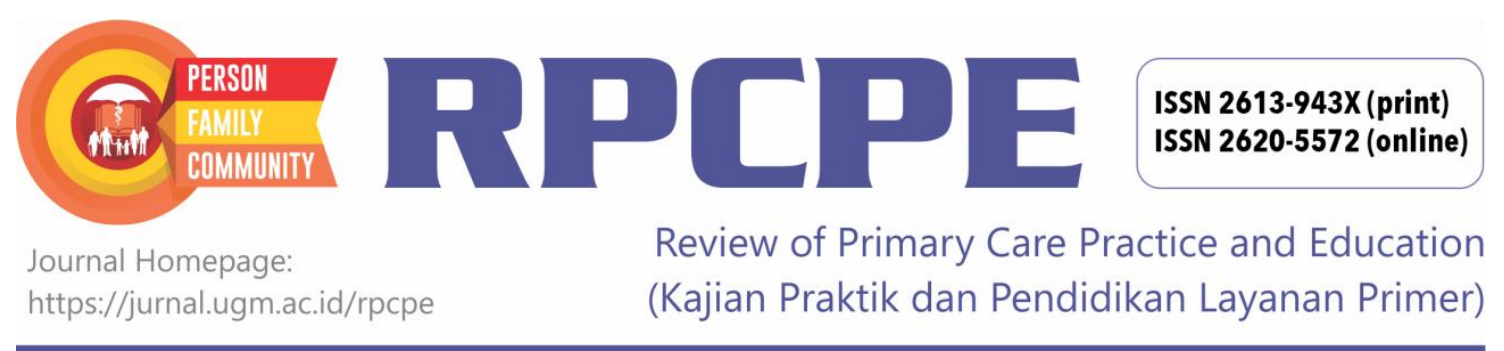

\title{
Benefits of Diabetes Support Group in Groups Chronic Disease Management Program (Prolanis) in Puskesmas Jetis II, Bantul District: A Case Study
}

\author{
Yulia Dewi Irawati ${ }^{1}$, Adi Heru Sutomo ${ }^{2}$, Mora Claramita ${ }^{3}$
}

\begin{abstract}
${ }^{1}$ Puskesmas Jetis II; Bantul; Yogyakarta; Indonesia
${ }^{2}$ Department of Family and Community Medicine; Faculty of Medicine, Public Health and Nursing; Universitas Gadjah Mada; Indonesia

${ }^{3}$ Department of Medical, Health Professions Education and Bioethics; Faculty of Medicine, Public Health and Nursing; Universitas Gadjah Mada; Indonesia
\end{abstract}

Corressponding Author:

Yulia Dewi Irawati: Puskesmas Jetis II, J1. Parangtritis Km 15, Jetis, Bantul, Yogyakarta, - 55781, Indonesia.

E-mail: yuliadewirawati@gmail.com

To cite this article:

Irawati YD, Sutomo AH, Claramita M. Benefits of diabetes support group in groups chronic disease management program (prolanis) in Puskesmas Jetis II, Bantul District: a case study. Rev Prim Care Prac and Educ. 2019; 2(1): 8-14.

\begin{abstract}
Background: Type 2 diabetes mellitus (T2DM) is a chronic disease that has the potential for complications which can affect the entire body so that it requires a comprehensive approach. This means that the management of T2DM must involve various parties, both medical, paramedic, patient, family and community. One strategy for managing T2DM is Prolanis (Chronic Disease Management Program) which is a diabetes support group at the Jetis II Health Center. To find out the success of Prolanis implementation, an evaluation of the benefits of the diabetes support group is needed. Objective: To find out the benefits obtained from participating in the diabetes support group in Prolanis at the Jetis II Bantul Health Center. Methods: A qualitative descriptive research was conducted with a case study approach. Data were obtained from patients with T2DM who are members of Prolanis (Chronic Disease Management Program) and officers of the Jetis II Health Center in Bantul Regency. Data were collected from patients with focus group discussions involving 30 resource persons divided into 3 groups. Additional data came from conducting independent interviews with 6 informants of the Puskesmas staff involved in the diabetes support group activities of Prolanis. Results: The benefits obtained from the diabetes support group are grouped into 3 categories, namely biopsychosocial support, information, and individual empowerment. Most patients especially felt the benefit from obtaining biopsychosocial support from the Prolanis group. Benefits for T2DM patients as Prolanis members also included getting information and individual empowerment. Conclusion: The benefits of a diabetes support group for T2DM patients in Prolanis members are getting biopsychosocial support, information, and individual empowerment.
\end{abstract}

Keywords: Type 2 diabetes mellitus, diabetes support group, Prolanis, Puskesmas

\section{INTRODUCTION}

Diabetes that is not managed properly can cause complications that result in death. Complications that often occur in diabetics include heart attacks, strokes, kidney failure, leg amputation, loss of vision and nerve damage. Diabetes is said to cause premature death and disability for sufferers. There are approximately 1.5 million deaths in the world caused by type 2 diabetes mellitus (T2DM).
Diabetes and its complications also bring considerable economic losses to sufferers, families, communities and the state ${ }^{1,2,3}$.

The 2013 Basic Health Research (Riskesdas) showed a 2fold increase compared to the 2007 Riskesdas data of 1.1 percent. The highest prevalence of the diagnosis of diabetes occurs in Yogyakarta at 2.6 percent. Diabetes is 
among the top 10 most common diseases in outpatient polyclinics in all Puskesmas in Bantul Regency, including in Jetis $\mathrm{II}^{4,5}$.

Management of T2DM is associated with the unhealthy lifestyle of patients so that changes in behavior or lifestyle of diabetic patients are needed to achieve better management outcomes. One strategy to change the behavior or lifestyle of diabetic patients is by using a support group ${ }^{6,7,8}$.

The form of the support group for diabetic patients in the Puskesmas is a diabetes support group. This support group conducts several group activities that are routinely done in Prolanis (Chronic Disease Management Program). Prolanis activities refer to the patient-centered care approach which makes patients' needs prioritized in managing diabetes ${ }^{9}$. The results of the study by Hermansyah and Yulistika reported that the patients' knowledge of Prolanis was very good (94\%) so that the condition of the blood sugar in Prolanis patients was well controlled ${ }^{10}$.

Prolanis activities have been held regularly since 2015 at the Jetis II Bantul Health Center. Activities offered in Prolanis include medical consultation, group education, a reminder through reminder SMS gateway, home visit, group activities, and monitoring health status ${ }^{11}$.

From the results of the preliminary study, it was reported that the target given by BPJS to Prolanis activities in Puskesmas was $50 \%$ or more of patients with T2DM. Jetis II Bantul Health Center has exceeded the target of $70 \%$. However, this achievement is not yet in line with the expectations of the vision and mission of Healthy Indonesia 2025. There are still many patients with T2DM in Jetis II Bantul Health Center who have not actively participated in Prolanis, the remaining 30\% of which are problems in achieving the vision and mission of Healthy Indonesia 2025.

The role of the diabetes support group is explained in the study that for respondents who do not have a support group, improvements in health status that occur at the beginning of therapy do not last long, and usually decrease within
6 months, while respondents who have support groups are better able to maintain or even improve their health status $^{12}$. Findings showed that the level of knowledge and medication adherence in patients who follow support groups such as the diabetes support group is higher than the group of patients who do not follow the diabetes support group ${ }^{13}$.

Regularly, diabetes support groups have been conducted at the Jetis II Bantul Health Center implementing Prolanis, but there are still many patients with T2DM who have not used these service facilities optimally. There has never been an evaluation of the benefits of a diabetes support group at Jetis II Health Center. For this reason, an evaluation is needed to determine the success of Prolanis as a diabetes support group. Based on the background described, this study aimed to find out the benefits of the diabetes support group in the Prolanis group (Chronic Disease Management Program) at the Jetis II Health Center, Bantul Regency.

\section{RESEARCH METHODS}

This study was a qualitative research with a case study design. The case study method was used in this study to explore situations that illustrate the implementation of the diabetes support group in Prolanis at the Jetis II Bantul Health Center.

The subjects of the study were T2DM patients in the Prolanis group and health workers involved in Prolanis, namely 1 Head of Community Health Center, 1 Prolanis officer, 1 Doctor, 1 Health Analyst, 1 Nutritionist, and 1 Pharmacist. Focus Group Discussion (FGD) was conducted with T2DM patients who are Prolanis group members. For health workers we conducted in-depth interviews. All results of the activities and data collection process were documented with recordings.

Patients with T2DM in the Prolanis group consisted of 30 people divided into 3 FGD groups, each group with 10 people (Table 1).

Table 1. Characteristics of FGD Participants

\begin{tabular}{cllc}
\hline No & Characteristics & Total \\
\hline 1 & Gender & Man & 1 \\
& & Woman & 29 \\
2 & Age & $>55$ Years & 15 \\
& & $45-55$ Years & 13 \\
& & $31-44$ Years & 2 \\
3 & \multirow{2}{*}{ Education } & $18-30$ Years & - \\
& & No taking education & 2 \\
& & Elementary School & 16 \\
\multirow{2}{*}{4} & \multirow{2}{*}{ How long as Prolanis member } & Junior High School & 6 \\
& & Senior High School & 6 \\
\multirow{2}{*}{5} & \multirow{2}{*}{ Guarantee Ownership } & $>1$ Years & 18 \\
& & $<1$ Year & 12 \\
& & JKN PBI & 25 \\
& & JKN Non PBI & 2 \\
& & JKN Self & 2 \\
\hline
\end{tabular}


The Focus Group Discussion guide was as follows:

1. What is the description of the implementation of the diabetes support group at the Jetis II Bantul Health Center?

2. What are the benefits of joining a Prolanis group?

3. How do health workers conduct Prolanis service delivery?

4. How are the facilities available for implementing Prolanis?

5. What are the obstacles or obstacles to implementing Prolanis?

Among the health center staff, in-depth interviews were done with the following in-depth interview guide:

1. What is the description of the implementation of the diabetes support group at the Jetis II Bantul Health Center?

2. What are the benefits of joining a Prolanis group?

3. How do health workers conduct Prolanis service delivery?

4. How are the facilities available for implementing Prolanis?

5. What are the obstacles to implementing Prolanis?

The validity of the data was reached by making data retrieval through utilizing sources outside the data that have been used as sources in the previous data collection ${ }^{14}$. Triangulation in testing credibility involved checking data from various sources, various ways, and various times ${ }^{15}$. In this study, the triangulation technique used source triangulation, namely data collection from 2 different sources, the T2DM patients and Puskesmas officers.

There are three main components that must be considered in the analysis of qualitative data, namely data reduction, data presentation and conclusion or verification ${ }^{14.15}$.

\section{RESULTS}

This qualitative study aimed to describe the benefits of the diabetes support group in patients with T2DM in the Prolanis group (Chronic Disease Management Program) at the Jetis II Bantul Health Center. Data from the results of this study were obtained through an FGD conducted with 30 T2DM patients belonging to the Jetis II Community Health Center Prolanis group. The 30 patients were divided into 3 FGD groups with each group consisting of 10 patients. The results of the recordings of the focus group discussions were made into transcripts which were read and analyzed for common content, then grouped into themes and sub-themes.

Other data in this study were obtained through in-depth interviews conducted with 6 health workers involved in the implementation of Prolanis in Jetis II Health Center, namely the Head of the Community Health Center, Provisional Executing Officers, Doctors, Health Analysts, Nutritionists, and Pharmacists. The results of the indepth interviews were transcribed and the results of the transcripts were read and analyzed for common content, then grouped into themes and sub-themes.

The researchers grouped the results of the FGD and in- depth interviews on the implementation of the diabetes support group in Prolanis activities in Jetis II Health Center into themes and sub-themes based on the references to the benefits of a diabetes support group according to Zriebiec (2003) which can be described as follows:

\section{Knowledge of the Diabetes Support Group}

As many as 28 of the 30 speakers in the FGD said that the gymnastics group that they had routinely followed was a support group intended for people suffering from diabetes mellitus.

“... I joined a group of gymnastics... I was given counseling ... for a chronic disease program ... for diabetes" (N2,5456)

The Diabetes support group in Prolanis is understood by the Jetis II Health Center staff as a government program that must be implemented. According to the Head of the Puskesmas the Prolanis is a program of BPJS that can affect the amount of capitation for the Jetis II Health Center. The quotations are as follows:

“... following the policy from above ... This must be provided by Puskesmas in connection with the requirements for BPJS credentials ... the implementation can be shared with PTM (Non-Communicable Disease Program)" (N1,29-33,49-50)

All medical staff and paramedics, when interviewed as resource persons, said that so far, they only did what became the central policy and carried out Prolanis routinely, but there was never an evaluation of the benefits of Prolanis specifically and they never evaluated the benefits of the diabetes support group for Prolanis members.

"What I know is that the Prolanis in the Jetis II Health Center is a group for DM patients whose activities are gymnastics, which is automatically given a drug once a month, after they have exercised ... then the officers involved are first doctors, then there are PTM programmers as part of the same Prolanis later if you need to consult with another place, what kind of dental or nutrition psychologist like that ...well, I only know Prolanis, for a group, not know more" (N5, 22-34) (N5,40-41)

The answers submitted by all health workers show that they have no knowledge of the implementation of the support group, which they understand is Prolanis as a government policy program that must be implemented.

\section{Benefits of the Diabetes Support Group}

\subsection{Information}

As many as 18 patients from 30 speakers in the FGD said there were benefits of getting health information obtained from health workers through counseling sessions, health consultations, and health counseling. The quotations are as follows:

“... many benefits, when in the hospital they were only told to take medicine many times, then eat and drink many times. Before I didn't know since the doctor didn't tell me just to take medicine three times. But here, they explained 
to eat first, 3 new breaths, then, take medicine and then eat again. The knowledge is very much here. " (N24,172-177)

Twenty-two patients also revealed that with this group there were benefits to add insight and exchange information with fellow T2DM patients in the Prolanis group. This is seen in the quotations as follows:

"Here we can exchange experiences about eating problems, health problems, with this group we have many benefits ... we know that eating rules, know that health is checked also Prolanis also the purpose is to maintain health and know the sugar fluctuation besides that also must be able to maintain healthy diet. " (N23, 154-160)

"There is this group. ... I think it's more influential ... I am happy about it." (N2,482-483)

The benefits of information in the form of patient knowledge about diabetes obtained by patients are not limited to face to face meeting with health workers during a medical consultation but patients also get the opportunity to get health education through counseling held by the Puskesmas. For patients, education sessions through counseling forums are very useful, and one quote that show this is:

"... counseling for me is very important because those who did not know about the diet pattern that patients with DM should eat, it is not possible if you check with the doctor, it is explained one by one, the time is up to give an explanation to the patient. At the Panembahan Hospital, they were told they should just not eat sweet things, but not which ones ... “ (N28,228-234)

\subsection{Biopsychosocial support}

From the FGD results, data obtained from 28 informants showed there were benefits in terms of biopsychosocial support, namely the existence of a sense of well-being, brotherhood, sharing, and the friendship between members that made patients happy when attending diabetes support group activities. Afterwards, patients feel healthy and the complaints that have been experienced so far are reduced and even disappear when participating in the gymnastics routine activities done by this group. A quotation that shows this is as follows:

"If not exercising do not participate in activities and do not take part in routine, my body feels rigid... doing gymnastics is good. Decreasing tension... sugar even though ... " (N12, 119-135)

The healthy feeling felt by patients after routinely taking part in the activities made patients feel happy when attending a diabetes support group meeting at Jetis II Health Center.

"... regulating sugar is stable and the blood circulation is smooth and relaxed because of participating in the exercise, the third, to burn the fat." (N24,94-99)

"First, I want to be healthy. Second, no pain in the body. If you don't do gymnastics, the body feels rigid. Medicine routine. Alhamdulillah is suitable to be screened for free."
$(\mathrm{N} 7,427-430)$

"want to be healthy, can reduce my blood sugar..." $(\mathrm{N} 3,63)$

Through Prolanis T2DM patients who are members of the diabetes support group also get the convenience of getting medication for one month which according to the patient it also makes it easier for patients. Patients also feel more attention by health workers more specific to their diabetes conditions.

"Yes, reducing the time to queue at the Puskesmas ... I used to go once every 10 days, now it's only one month, it's economical ... because when queuing up... sometimes I'm dizzy." (N13,770-779)

"..Is the control, note that everything about the disease is considered but also more specific ..." (N13,137-142)

Clinically, the patient revealed that their health condition was even better after joining the diabetes support group. The healthy feeling was felt by patients after routinely taking part in the activities held so that patients feel happy when attending a diabetes support group meeting at the Jetis II Health Center.

"The first reason to join was I want to be healthy, regulating sugar so that it can stabilize and have smooth blood circulation which becomes relaxed because of participating in the exercise, the third one will burn fat so that I will sweat," (N24,94-99)

"How healthy is it, reduced blood sugar for my noodles ..." (N3,63)

“... at first my heart was slow in my gymnastics but changed into a healthy way, number two, with the new friends such as Kodok." (N7,225-231)

Health staff informants in the interviews revealed that with Prolanis the treatment of T2DM patients increased, patients were more understanding when given health education and they participated in gymnastics. All of these activities were useful in preventing the complications of diabetes, as the results of the interviews showed:

"... can help in managing diabetes in patients when viewed from adherence to taking medication, diligent control, and so there is physical activity and often counseling about diseases to Prolanis members, yes, the hope is that DM patients can control their sugar levels more so it is intended for comprehensive management among the officers here ... to prevent complications." (N3,81-9)

Most patients express the benefits of the experience of pleasure when meeting with friends who are members of the diabetes support group. This is expressed in the following quotation:

"... happy for meeting with the mothers... meet ... together sick ... there is a fee... if there are those who go to the hospital there is little for 100 thousand social funds. If this group has visited friend ... then you can share it ... sincerely with the condition of blood sugar ... more 
enthusiastic ... same ... It's great it feels like there is a sense of ... Brotherhood ..., to add relatives and friend."

\subsection{Individual Empowerment}

From the FGD results, there was 1 patient who said that the diabetes support group should be able to be effective so that patients can control their blood sugar levels. According to the patient, an activity is needed so that Prolanis group with T2DM patients can be motivated to reduce their blood sugar levels. This is in accordance with the following quote:

"So, we are depending on the individual, how about if the diet is a bit strict if you want to program a month ahead, the program for diabetes, for example, we have to adjust our diet ... what if our friends lowered the laboratory numbers so we have the spirit to compete just like that ... so there is enthusiasm to recover to stabilize down. If it's going up and down and going up and down, what if we have a plan starting next month to compete against other patients." (N29,329-342)

From the data above, the knowledge of the concepts of a diabetes support group in the implementation of Prolanis in the Jetis II Health Center is unknown to both health workers and patients themselves. However, diabetes support group activities are routinely done in Jetis II Health Center for T2DM patients in Prolanis members, who get benefits from the support group including the benefits of getting information, biopsychosocial support, and community empowerment.

\section{DISCUSSION}

\section{A. Knowledge}

Based on the results of the FGD, the majority of patients understood the diabetes support group as a Prolanis group consisting of diabetic patients with regular exercise every week. Meanwhile, the results of interviews with health workers found all officers said that they understood Prolanis as a policy program from above that had to be implemented and they also did not have specific knowledge about the diabetes support group.

This finding explains why there is a narrow understanding of patients about the diabetes support group because of the limited information obtained by patients from health workers who also do not understand the concepts of the support group. Organizing a diabetes management program needs good knowledge and understanding starting from identifying problems, means for solutions and supports, and factors that exist or are expected to emerge. By empowering all potentials, both human resources and health institutions and their supporting devices (organizations), it is hoped that all will lead to achieving the best diabetes management results ${ }^{16}$.

The definition of a support group is a group of people who are in the same condition and/or a group of people who care about certain conditions such as diabetes support group. The diabetes support group in Prolanis Jetis II Health Center is one of the secondary preventive efforts that can be done to help manage diabetes. A good support group must have proper planning that is through several stages, namely: the belief of group members in the usefulness and effectiveness of the support group, the existence of supporting institutions, and clear group concepts ${ }^{17}$.

\section{B. Benefits}

Based on data obtained about the benefits of the diabetes support group the results are illustrated as follows:

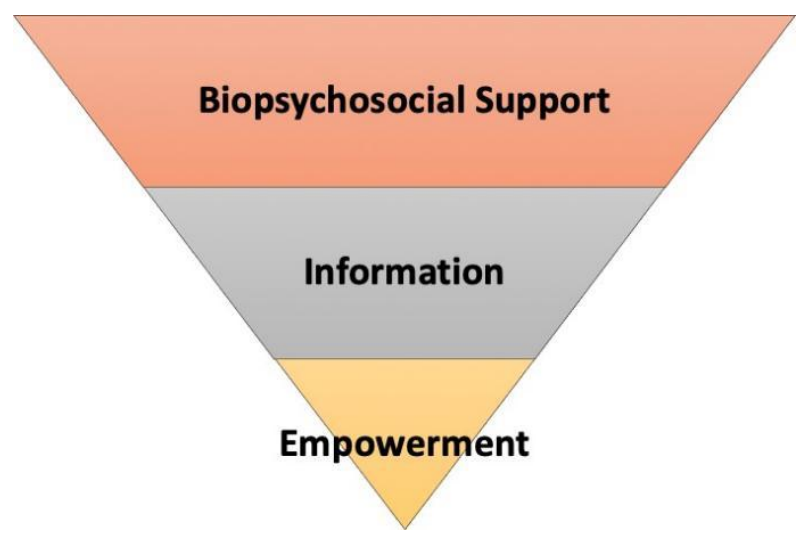

\section{B.1. Biopsychosocial support}

Most patients claim to have benefited especially from the biopsychosocial support since they joined the diabetes support group. Physically, many complaints are reduced and they feel healthy. Positive feelings that arise include: being in the same boat, brotherhood, sharing hopes, experiences, fears, and worries during suffering from diabetes. These feelings generate a sense of sincerity towards their condition and more enthusiasm for treatment.

In line with the data obtained from health staff sources, there was a difference in the level of adherence to treatment in Prolanis patients when compared to non Prolanis patients. This finding is consistent with research that shows that the level of knowledge and medication adherence in patients who follow support groups such as diabetes support group is higher than the group of patients who do not follow the support group. The creation of equality of perspectives between officers and patients will also improve patient compliance in treatment ${ }^{13,18}$.

Nevertheless, the data obtained from the FGD still show many patients who clinically have blood sugar levels that are still unstable, going up and down alternately. From the results of interviews with health workers, similar data were found that the clinical parameters of Prolanis patients were not significantly different compared to those not in Prolanis. This result is in accordance with the results of the study which stated that there were no significant differences in clinical parameters between patients given education in support groups with patients who did not join the support group ${ }^{19}$.

The healthy feelings that the patients have with the fact that there is no significant improvement in the clinical parameters of the patient show that there is a subjective condition but objectively the cure is not obtained, instead patients recover from "illness" rather than recover from 
the "disease" 9.

\section{B.2. Information}

Patients with T2DM from the Jetis II Community Health Center Prolanis group revealed the importance of the information they obtained from participating in the support group. Information was obtained through exchanging experiences and insights with fellow members. Information was also obtained from Puskesmas officers through medical consultations and group education. According to Nair et al. (2007) the patient's assessment of the benefits and risks of treatment is a continuous process and requires continuous interaction with the health system to always provide an understanding of the condition of diabetes ${ }^{20}$.

In the Prolanis group of Jetis II Health Center, the results of the study showed that more information was obtained from Puskesmas officers and there was no specific session that explored the experiences of each group member in dealing with diabetes. Whereas according to Zriebiec, receiving constructive information, suggestions, or criticism from other people who experience the same problem may be easier than accepting the same advice from health care professionals $^{17}$.

\section{B.3. Individual empowerment}

The benefits of empowerment that can be found in the support group at Jetis II Health Center are only found in a few patients. Empowerment is a strategic issue that is often sought through inpatient health efforts. Research in India supports this opinion that support groups are one strategy that is effective and does not require large costs to generate patient empowerment so that it can influence changes in lifestyle and patient behavior so that blood sugar levels can be controlled and health status can be better ${ }^{21}$.

According to the reference from WHO to create empowerment, 4 basic components are needed, namely, the patient understands his role, sufficient knowledge to be able to take over the activities and relate to the officer, the environment that facilitates, and skills improvement. At the Jetis II Health Center, the basic components were not fulfilled, which would make the patient become the expert person about his own health condition. Patients do not understand their role as patients because of the lack of knowledge of patients and health center staff about a good support group. Individual empowerment is the final result expected in the application of patient-centered care which is one of the principles of Family Medicine. The role of family doctors has a strategic position as a driver of strength that exists in patients and stimulates the ability of patients to be self-regulating so that a dynamic therapeutic process is carried out and produces better health status ${ }^{22}$.

Accordingly, based on the analysis of researchers about the description of the benefits of a diabetes support group in Prolanis shown by the illustration of the reverse triangle. The inverse triangle with the benefits of biopsychosocial is at the top position and the benefits of empowerment are in the least position explaining the reality of the conditions of the T2DM patients who are members of the Prolanis group. They are recovering from illness but disease recovery is not achieved. They become empowered to make themselves healthy as a whole person. The impact of empowerment that few patients get causes achievement of health status that is not optimal according to these expectations because the health achieved is not comprehensive physically and psychologically. So, the successful management of T2DM patients through Prolanis has not been optimally suited to Prolanis' goal of encouraging patient independence to achieve a better quality of life.

The results of this study besides being applied to the Jetis II Health Center, can also possibly occur at other health centers that have the same characteristics and conditions.

\section{The limitations of this study}

The limitations of this study include the subjectivity of the researcher, since the research depends on the interpretation of the researcher about the meaning implied by the results of the study so that the bias tendency persists. Another limitation is the lack of understanding of the respondents to the research questions.

Recommendations for researchers who will conduct similar research encourage using data retrieval obtained from patients' perceptions carried out in in-depth interviews to further explore the patient's experience when joining the Prolanis diabetes support group. This research is still a preliminary study and more in-depth research needs to be done about the benefits obtained by a support group for patient outcomes if using clinical parameters.

\section{CONCLUSIONS}

The diabetes support group at Jetis II Community Health Center was done in Prolanis activities routinely with the participants as patients with T2DM of Prolanis group members.

Results showed the implementation of the diabetes support group in Prolanis is not yet in line with the ideal concepts of a diabetes support group because of the limited knowledge of Puskesmas officers even though there are several benefits from the support group: biopsychosocial support, getting information and community empowerment.

The benefits of the diabetes support group in Prolanis are shown by an inverted triangle illustration. The inverse triangle with the benefits of biopsychosocial at the top and the benefits of empowerment in the lower position is explaining the reality of the conditions of T2DM patients who are members of the Prolanis group are recovering from "illness" but no cure is achieved for the "disease".

The impact of little or low empowerment in patients causes the achievement of health status that is not optimal according to expectations because the health obtained is not comprehensive physically and psychologically. As a result, the successful management of T2DM patients through Prolanis has not been optimal in accordance with Prolanis' goal of encouraging patient independence to achieve good health status.

For this reason, it is recommended that all Puskesmas make the Prolanis implementation evaluation team, conduct an 
evaluation of Prolanis implementation, create activities in the diabetes support group that can motivate Prolanis group members to compete in improving their health status and understand and implement activities according to Prolanis technical guidelines from BPJS. For BPJS, it is necessary to hold meetings with the Health Office and Puskesmas to discuss the effectiveness of the support group for Prolanis success, so that the implementation of Prolanis can be in accordance with the aims and objectives and can achieve the expected target of this Prolanis program. For the future, further research is needed on the effect of a diabetes support group on clinical parameters of T2DM patients.

\section{Acknowledgment}

Our profound thanks go to all the people who were willing to participate in this research. We also express our gratitude to friends at the Jetis II Health Center who have helped this research.

\section{Ethical Approval and Informed Consent}

This study was approved by The Medical and Health Research Ethical Committee (MHREC) from the Faculty of Medicine, Public Health and Nursing, Universitas Gadjah Mada, Yogyakarta with reference number: KE / FK / 1321 / EC / 2017.

\section{Funding}

Self-funding.

\section{Availability of Data and Material}

For readers who want to access data and material, please contact the author via e-mail at: yuliadewirawati@gmail. com

\section{Conflict of interest}

None.

\section{REFERENCES}

1. World Health Organization. Global report on diabetes. Geneva: World Health Organization. 2016.

2. International Diabetes Federation/IDF. IDF diabetes atlas. 4th edition, IDF, Brossels, Belgium. 2016.

3. World Health Organization. Chronic Disease Are The Major Cause of Death and Disability Worldwide. Geneva: Facing The Fact World Health Organization. 2002.

4. Riskesdas. Riset Kesehatan Dasar. Basic Health Research. Health Research and Development Agency of the Indonesian Ministry of Health. Jakarta: Litbangkes Agency, Depkes RI. 2013.

5. Bantul District Health Office. Bantul District health profile 2017. Bantul: Bantul District Health Office. 2017.

6. Soegondo S, Soewondo P, Subekti I. Integrated diabetes management. Jakarta: Faculty of Medicine, Universitas Indonesia. 2007.

7. Paul S, Charura D. 12 The relationship in group therapy. The therapeutic relationship handbook: Theory and practice. 2014 Oct $1 ; 1(1): 131$

8. Powers MA, Bardsley J, Cypress M, Duker P, Funnell MM, Fischl $\mathrm{AH}$, et al. Diabetes self-management education and support in type 2 diabetes: a joint position statement of the American Diabetes Association, the American Association of Diabetes Educators, and the Academy of Nutrition and Dietetics. The Diabetes Educator. 2017 Feb;43(1):40-53.

9. McWhinney IR, Freeman T. Textbook of family medicine. Oxford University Press. 2009.

10. Hermansyah, A. \& Yulistika, D. Evaluation of Prolanis activities in the Work Area of North Purwokerto I Health Center, Banyumas Regency in 2016 [Thesis] (not published). Surakarta: Faculty of Health Sciences,Muhammadiyah University Purwakarta. 2016.
11. BPJS. Practical Guide: Prolanis (Chronic Disease Management Program). Jakarta: BPJS Health. 2014.

12. Tang TS, Funnell MM, Oh M. Peer reviewed: Lasting effects of a 2-year diabetes self-management support intervention: Outcomes at 1-year follow-up. Preventing Chronic Disease. 2012;9.

13. Izzah Z, Suprapti B, Aryani T, Budiatin AS, Rohmadi M, etc. Support groups for diabetes improve compliance and control of patients' blood glucose levels. Indonesian Clinical Pharmacy Journal. 2013;2(3):94-101.

14. Moleong LJ. Qualitative research methodology. Bandung: Remaja Rosdakarya. 2011.

15. Sugiyono. Quantitative, qualitative research methods and R \& D. Bandung: Alfabeta. 2009.

16. Soegondo S, Soewondo $\mathrm{P}$, Subekti I. Integrated diabetes management. Jakarta: Faculty of Medicine, Universitas Indonesia. 2007.

17. Zrebiec J. Tips for running a successful group. Diabetes Spectrum. 2003 Apr 1;16(2):108-11.

18. Brundisini F, Vanstone M, Hulan D, DeJean D, Giacomini M. Type 2 diabetes patients' and providers' differing perspectives on medication nonadherence: A qualitative meta-synthesis. BMC HealthServices Research. 2015 Jun;15(1):516.

19. Sachmechi I, Wang A, Kim P, Reich D, Payne H, Salvador VB. Impact of diabetes education and peer support group on the metabolic parameters of patients with diabetes mellitus (type 1 and type 2). British Journal of Medical Practitioners. 2013 Dec 1;6(4):10-5.

20. Nair KM, Levine MA, Lohfeld LH, Gerstein HC. "I take what I think works for me": A qualitative study to explore the patient perception of diabetes treatment benefits and risks. Journal of Population Therapeutics and Clinical Pharmacology. 2007;14(2).

21. Aswathy S, Unnikrishnan AG, Kalra S, Leelamoni K. Peer support as a strategy for effective management of diabetes in India. Indian Journal of Endocrinology and Metabolism. 2013 Jan;17(1):5.

22. Mola E, Eriksson T, Allen J, Gay B, Crebolder H, Catholic J. The European definition of general practice/family medicine. WONCA EUROPE. 2011. 